\title{
Molecular Characterization of the Two Types of Fruit Colour of Carica papaya $\mathbf{L}$
}

\author{
Wahua $\mathrm{C}^{1 *}$, Odogwu $\mathrm{BA}^{1}$, Adolga $\mathrm{EO}^{1}$ and Agba $\mathrm{JB}^{1}$
}

${ }^{1}$ Department of Plant Science and Biotechnology, Faculty of Science University of Port Harcourt, Port Harcourt, Rivers State, Nigeria

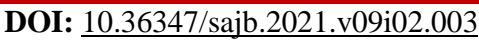

| Received: 24.02.2020 | Accepted: 09.03.2020 | Published: 18.02.2021

*Corresponding author: Wahua $\mathrm{C}$

Abstract

Original Research Article

Papaya (Carica papaya Linn.) is an important crop with high pro-vitamin A carotenoids content. In Nigeria, the major papaya fruit flesh colours observed is the yellow and red-fleshed varieties. To differentiate the yellow and red-fleshed papaya varieties, a study carried out to genetically delineate the yellow and red-fleshed papaya varieties to establish their phylogenetic relationship and varietal differences using molecular markers as a diagnostic tool. DNA was extracted from the young leaves of the yellow- and red-fleshed varieties at the Regional Centre for Biotechnology and Bioresources Research Centre, University of Port Harcourt with ZYMO Quick-DNATM Plant/Seed Miniprep Kit. The gDNA quantity and concentration were measured using the Nanodrop 2000c spectrophotometer and Agarose gel electrophoresis. The gDNA samples were shipped to the International Institute of Tropical Agriculture (IITA) Bioscience Center, Ibadan, for amplification using the Ribulose-1, 5-biphosphate carboxylase $(r b c L)$ primers and the amplicons were sequenced using the ABI3500 capillary electrophoresis sequencer. The DNA sequence file was saved in the Bioedit file with extension .$a b 1$. The sequence was analyzed using the Molecular Evolutionary Genetics Analysis (MEGA) version 7.0.26 software, and aligned using the Basic Local Alignment Search Tool for nucleotide (BLASTN) 2.8.0 version of the National Center for Biotechnology Information (NCBI) database. The amplified DNA sequences of the two papaya varieties yielded 580 base pairs. The result of the taxonomy report generated from the sequences of the two papaya varieties matched 64 sequences of the members of the Caricaeae family, of which 21 sequences hits matched Carica papaya and 23 sequences hits matched the Vasconcella genus. The BLAST phylogenetic tree indicated that both papaya species were grouped together with Carica papaya cultivars in the NCBI database. Also, the sequences of the yellow-fleshed papaya (NKECHI_RBCL_6) and red-fleshed papaya (NKECHI_RBCL_9) were 100\% and 99.63\% identical to Carica papaya clone 14 accession number KX951436 sequences deposited at the NCBI database. This finding indicates that Carica papaya clone 14 was probably a yellow-fleshed papaya variety. Therefore, the Ribulose-1, 5-biphosphate carboxylase $(R B C l)$ molecular marker was able to detect this difference between the yellow and red-fleshed papaya varieties. Consequently, these findings will provide information for the molecular database of papaya and will be useful for the papaya conservation and crop improvement programs.

Keywords: Papaya, Rbcl marker, evolutionary relationship, BLAST.

Copyright (C) 2021 The Author(s): This is an open-access article distributed under the terms of the Creative Commons Attribution 4.0 International License (CC BY-NC 4.0) which permits unrestricted use, distribution, and reproduction in any medium for non-commercial use provided the original author and source are credited.

\section{INTRODUCTION}

In Nigeria, Carica papaya Linn. Commonly referred to as 'pawpaw or papaya' (English); Indu (Ijo, Nembe); Ojo (Ikwerre); Etihi-mbakara (Efik) [1], is the most economically important species of the family Caricaceae. Taxonomically, the Carica papaya plant is usually described as a dioeciously, rarely herbaceous tree in which hermaphrodite forms do occur [2]. According to Purselove [2], papaya attains a height between $4-6 \mathrm{~m}$. The stem is straight, cylindrical with prominent leaf scars, hollow, about $10-30 \mathrm{~cm}$ in diameter with spongy tissue core. The leaves are large, compound palmate, clustered near the apex of the trunk. The phyllotaxy is spiral and the petiole is $25-100 \mathrm{~cm}$ long, hollow and pale green or tinged purple. Papaya flowers can be grouped into three basic forms that reflect the whole plant gender: female, male or bisexual (hermaphrodite). With controlled cross-pollinations between flowers of each gender, the ratio of female, hermaphrodite and male offspring are predictable. The unisexual flowers are actinomorphic that are off-white in colour. The fruit of $C$. papaya is a fleshy berry, about $7-30 \mathrm{~cm}$ long and about $9 \mathrm{~kg}$ in weight; spherical to ovoid-oblong when produced from pistillate flowers but pyriform, grooved or cylindrical when produced from hermaphrodite flowers. The skin of the fruit in all cases is thin, smooth and green turning yellow or orange when 
Wahua C et al., Sch Acad J Biosci, Feb, 2021; 9(2): 29-35

ripe. Central cavity of the fruit is usually five (5) angled. Seeds are numerous, parietal and attached in five rows to the interior wall of the ovary. Individual seeds are spherical, black or grey wrinkled and about $5 \mathrm{~mm}$ in diameter.

C. papaya is not only cultivated for its delicious and vitamin C-rich fruits, but also because it produces the enzyme papain, which is used in food and pharmaceutical industries [3] The leaves and unripe fruits contain milky juice which is the protein-ferment, papain, collected and used as digestive salt for tenderizing meat [1]. Besides this economic value, papaya fruit provides valuable amounts of micronutrients, in particular several pro-vitamin-A carotenoids. The colour of papaya fruit flesh is determined largely by the presence of carotenoid pigments with red and yellow being the two major papaya fruit flesh colours [4]. Carotenoid pigments are indispensable for photosynthesis in plants. In many species, carotenoids can also accumulate as secondary metabolites in chromoplasts of flowers, fruits, seeds or roots to provide distinct coloration, ranging from yellow to orange and red [5]. These flesh colours are controlled by a single genetic locus with yellow being dominant over red [6]. Besides, the yellow-fleshed fruit contains $\beta$-carotene while the red-fleshed papaya fruit has high levels of lycopene and the conversion of lycopene to $\beta$-carotene is catalyzed by the lycopene $\beta$-cyclase hormone [4]. Red-fleshed papaya fruit contain lycopene, whilst this pigment is absent from yellow-fleshed fruit. The conversion of lycopene (red) to b-carotene (yellow) is catalyzed by lycopene b-cyclase. Therefore, different papaya fruit flesh colours observed could be due to differences in the carotenoids content. In tropical countries, papaya fruit represents an important pro-vitamin A source, because vitamin A-rich animal foods such as eggs and milk products are expensive for the majority of the population [7]. Therefore, papaya genotypes containing both lycopene and pro-vitamin A carotenoids may represent a valuable nutritional component of the human diet [7].

Various mechanisms have been reported for the differential accumulation of carotenoids among different varieties. There are several methods of differentiating the yellow and red-fleshed papaya varieties [5, 4]. One of such methods is the use of molecular markers. Papaya species represents an important model in genetic and genomic studies; because papaya is one of the first plant species to have its genome sequenced [8] Knowledge of the genetic diversity within this crop species is essential to understand their origin, domestication and evolutionary relationships, and to efficiently develop strategies for the conservation of their genetic resources, and effective crop improvement [9]. According to Schweiggert et al. [7], carotenoid levels among a set of hybrids and lines differed significantly which supports the hypothesis of an exploitable genetic variability, and a potential heterotic effect regarding carotenoid expression which may be instrumental in papaya breeding programs. Also, the provitamin a carotenoids and total lycopene were significantly of higher levels particularly in red-fleshed hybrids. The breadth of genetic variation readily available for papaya breeding and improvement is difficult to estimate. Therefore, the aim of this study was to genetically delineate the yellow and red-fleshed papaya varieties to establish their phylogenetic relationship and varietal differences using molecular markers as a diagnostic tool.

\section{MATERIALS AND METHODS Source of plant materials}

To extract the genomic DNA study, ripe fruits of Carica papaya from the red and yellow varieties used for the study were purchased from the daily market in Choba town in Rivers State, Nigeria. The seeds were extracted from the fruits, air-dried and then planted in disposable cups at the Center for Ecological Studies, University of Port Harcourt, Choba. Rivers state $\left(4^{0} 52\right.$ ' 44 " North, 60 55' 20" East).

\section{Molecular characterization using the Simple Sequence Repeat (SSR) marker and identification \\ The young leaves of the yellow- and} red-fleshed Carica papaya were collected on ice moved to the Regional Centre for Biotechnology and Bioresources Research Centre, University of Port Harcourt (coordinates). Extraction of genomic DNA (gDNA) from Carica papaya was done using the ZYMO Quick-DNA $^{\text {TM }}$ Plant/Seed Miniprep Kit (Zymo Research Group, California, USA). The gDNA quantity and concentration were measured using the Nanodrop 2000c spectrophotometer (Thermo fisher Scientific Inc. Wilmington, Delaware, USA). The DNA purity was measured as a ratio of absorbance at 280 nanometer $(\mathrm{nm})$ to that of 260 nanometer. The quality of the gDNA was further quantified using the Agarose gel electrophoresis performed according to the modified method of Saghai-Maroof et al. [10] and diluted to $50 \mathrm{ng} / \mu \mathrm{l}$. The gDNA samples were shipped to the International Institute of Tropical Agriculture (IITA) Bioscience Center, Ibadan, Nigeria for amplification and sequencing. The Ribulose-1, 5-biphosphate carboxylase $(r b c L)$ primers was used; $r b c L-F$ as forward primers and $r b c L-\mathrm{R}$ as reverse primers, $r b c L-\mathrm{F}$ (5'-CCACAAACAGAGACTAAAGC -3') and rbcL-R (5'- GTAAAATCAAGTCCACCGCG -3') were used to amplify the fragments of nuclear ribosomal DNA (rDNA). The amplicons were sequenced using the ABI3500 capillary electrophoresis sequencer. The DNA sequence file was saved in the Bioedit file with extension .$a b 1$. The sequence was analyzed using the Molecular Evolutionary Genetics Analysis (MEGA) version 7.0.26 software, and aligned using the Basic Local Alignment Search Tool for nucleotide (BLASTN) 2.8.0 version of the National Center for Biotechnology Information (NCBI) database. 


\section{RESULTS}

The result of the genomic DNA concentration of the yellow-fleshed and red-fleshed are presented in Table 1. The yellow-fleshed papaya (NKECHI_RBCL_6a and (NKECHI_RBCL_6b)) were $46.7 \mathrm{ng} / \mu \mathrm{l}$ and $48.5 \mathrm{ng} / \mu \mathrm{l}$ respectively, while the red-fleshed variety (NKECHI_RBCL_9a and
(NKECHI_RBCL_9b) were $109 \mathrm{ng} / \mu \mathrm{l}$ to $180.9 \mathrm{ng} / \mu \mathrm{l}$ respectively. This indicates that the concentration of the DNA was good for sequencing. The purity ratio was measured by the absorbance ratio A260/280nm which ranged from $1.59 \mathrm{~nm}$ to $1.83 \mathrm{~nm}$ while the A260/230nm ratio ranged from $0.69 \mathrm{~nm}$ to $1.05 \mathrm{~nm}$.

Table-1: Nanodrop reading of the extracted nucleic acid (DNA) from the yellow-fleshed and red-fleshed papaya

\begin{tabular}{|c|c|c|c|c|c|c|c|c|c|}
\hline & Sample ID* & User name & Date and Time & $\begin{array}{l}\text { Nucleic Acid } \\
\text { Conc. }(n g / \mu \mathrm{l})\end{array}$ & A260 & A280 & $\begin{array}{l}\text { A260/2 } \\
80\end{array}$ & $\begin{array}{l}\text { A260/2 } \\
30\end{array}$ & $\begin{array}{l}\text { Fact } \\
\text { or }\end{array}$ \\
\hline 1 & $\begin{array}{r}\text { NKECHI_RBCL } \\
\text {-6a }\end{array}$ & $\begin{array}{l}\text { RCBBR-UN } \\
\text { IPORT }\end{array}$ & 6/26/2018 1:02:37 PM & 48.5 & 0.969 & 0.608 & 1.59 & 1.05 & 50 \\
\hline 2 & $\begin{array}{r}\text { NKECHI_RBCL } \\
\_6 \mathrm{~b}\end{array}$ & $\begin{array}{l}\text { RCBBR-UN } \\
\text { IPORT }\end{array}$ & 6/26/2018 1:03:35 PM & 46.7 & 0.933 & 0.567 & 1.65 & 1.03 & 50 \\
\hline 3 & $\begin{array}{r}\text { NKECHI_RBCL } \\
\_9 \mathrm{a}\end{array}$ & $\begin{array}{l}\text { RCBBR-UN } \\
\text { IPORT }\end{array}$ & 6/26/2018 1:09:04 PM & 180.9 & 3.617 & 1.976 & 1.83 & 0.69 & 50 \\
\hline 4 & $\begin{array}{r}\text { NKECHI_RBCL } \\
\_9 \mathrm{~b}\end{array}$ & $\begin{array}{l}\text { RCBBR-UN } \\
\text { IPORT }\end{array}$ & 6/26/2018 1:10:10 PM & 109 & 2.181 & 1.26 & 1.73 & 0.71 & 50 \\
\hline
\end{tabular}

*NKECHI_RBCL_6 represents the yellow-fleshed papaya and NKECHI_RBCL_9 represents the red-fleshed papaya.

The result of the amplified PCR product generated from the yellow-fleshed and red-fleshed papaya is shown in Plate 2. The amplified DNA showed a band on gel when observed under UV light. From the result, the ladder used indicated that the DNA sequences of the four papaya samples had over 580 base pairs.

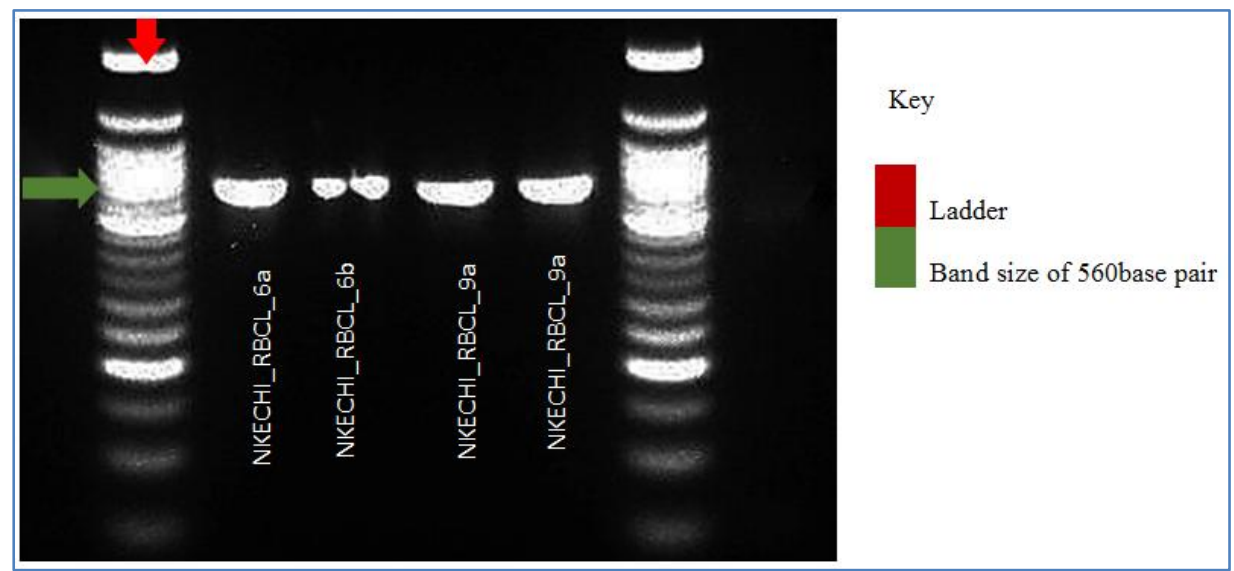

Plate-2: Amplified DNA sequence of the yellow- [NKECHI_RBCL_6] and red-fleshed [NKECHI_RBCL_9] papaya

The result of taxonomy report generated from the sequences of the yellow-fleshed and red-fleshed papaya is shown in Figure 1. The two query sequences matched 64 sequences of the members of the Caricaeae family, of which 21 sequences hits matched Carica papaya and 23 sequences hits matched the Vasconcella genus. 


\begin{tabular}{|c|c|c|c|c|c|}
\hline \multicolumn{3}{|c|}{ Graphic Summary } & \multirow{2}{*}{$\begin{array}{l}\text { Alignments } \\
\text { Taxonomy }\end{array}$} & \multicolumn{2}{|l|}{ Taxonomy } \\
\hline Reports & Lineage & Organism & & & \\
\hline \multicolumn{6}{|c|}{100 sequences selected 2} \\
\hline \multicolumn{3}{|c|}{ Taxonomy } & Number of hits & Number of Organisms & Description \\
\hline \multicolumn{3}{|c|}{ 日Magnoliopsida } & 109 & 36 & \\
\hline \multicolumn{3}{|c|}{. EPentapetalae } & 107 & 34 & \\
\hline \multicolumn{3}{|c|}{. . 日Brassicales } & 106 & 33 & \\
\hline \multicolumn{3}{|c|}{... $\boxminus$ Caricaceae } & $\underline{64}$ & 28 & \\
\hline \multicolumn{3}{|c|}{. . . Carica papaya } & $\underline{21}$ & 1 & Carica papaya hits \\
\hline \multicolumn{3}{|c|}{.... घVasconcellea } & $\underline{23}$ & 16 & \\
\hline \multicolumn{3}{|c|}{. . . V Vasconcellea cf. goudotiana HCAR167 } & 1 & 1 & Vasconcellea cf. goudotiana HCAR167 hits \\
\hline \multicolumn{3}{|c|}{. . . . V Vasconcellea crassipetala } & 1 & 1 & Vasconcellea crassipetala hits \\
\hline \multicolumn{3}{|c|}{. . . . Vasconcellea monoica } & $\underline{2}$ & 1 & Vasconcellea monoica hits \\
\hline \multicolumn{3}{|c|}{. . . . Vasconcellea sphaerocarpa } & $\underline{2}$ & 1 & Vasconcellea sphaerocarpa hits \\
\hline \multicolumn{3}{|c|}{. . . . Vasconcellea cauliflora } & $\underline{2}$ & 1 & Vasconcellea cauliflora hits \\
\hline \multicolumn{3}{|c|}{$\ldots$. Vasconcellea chilensis } & $\underline{2}$ & 1 & $\underline{\text { Vasconcellea chilensis hits }}$ \\
\hline \multicolumn{3}{|c|}{. . . . Vasconcellea quercifolia } & $\underline{2}$ & 1 & Vasconcellea quercifolia hits \\
\hline \multicolumn{3}{|c|}{. . . V Vasconcellea pariflora } & $\underline{2}$ & 1 & Vasconcellea parviflora hits \\
\hline \multicolumn{3}{|c|}{. . . . Vasconcellea microcarpa } & 1 & 1 & Vasconcellea microcarpa hits \\
\hline \multicolumn{3}{|c|}{$\ldots$. Vasconcellea cundinamarcensis } & $\underline{2}$ & 1 & Vasconcellea cundinamarcensis hits \\
\hline \multicolumn{3}{|c|}{. . . . Vasconcellea sprucei } & 1 & 1 & Vasconcellea sprucei hits \\
\hline \multicolumn{3}{|c|}{.... Vasconcellea palandensis } & 1 & 1 & Vasconcellea palandensis hits \\
\hline \multicolumn{3}{|c|}{.... Vasconcellea glandulosa } & 1 & 1 & Vasconcellea glandulosa hits \\
\hline \multicolumn{3}{|c|}{. . . . V Vasconcellea stipulata } & 1 & 1 & Vasconcellea stipulata hits \\
\hline \multicolumn{3}{|c|}{.... Vasconcellea $x$ heilbornii } & 1 & 1 & Vasconcellea $x$ heilbornii hits \\
\hline \multicolumn{3}{|c|}{$\ldots$ Vasconcellea candicans } & 1 & 1 & Vasconcellea candicans hits \\
\hline
\end{tabular}

Fig-1: The taxonomy report of the sequences of the yellow-fleshed and red-fleshed papaya

The result of the BLAST phylogenetic tree view is presented in Figure 2. From the phylogenetic tree, both papaya species (in yellow) were grouped together with ten Carica papaya cultivars, one Dianthus cryophyllus and five Vasconcella species in the NCBI database.

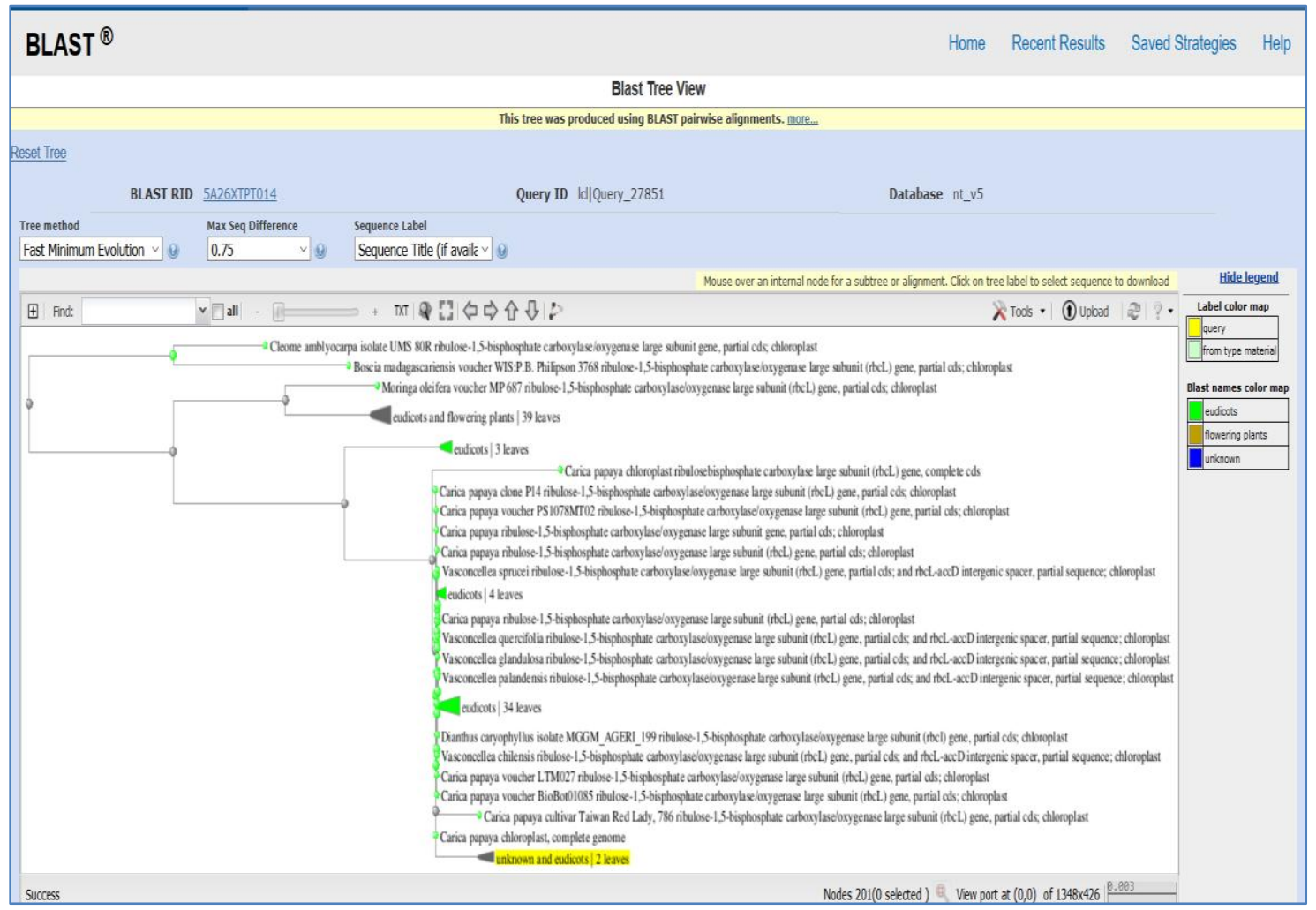

Fig-2: The BLAST phylogenetic tree view 
The result of the sequences producing significant alignments are presented in Figure $3 \mathrm{~A}$ and 3B. The yellow-fleshed papaya (NKECHI_RBCL_6) and red-fleshed papaya (NKECHI_RBCL_9) had query length of 570 and 569 base pairs respectively and was $100 \%$ and $99.63 \%$ identical to Carica papaya clone 14 accession number KX951436 sequences deposited at the NCBI database.

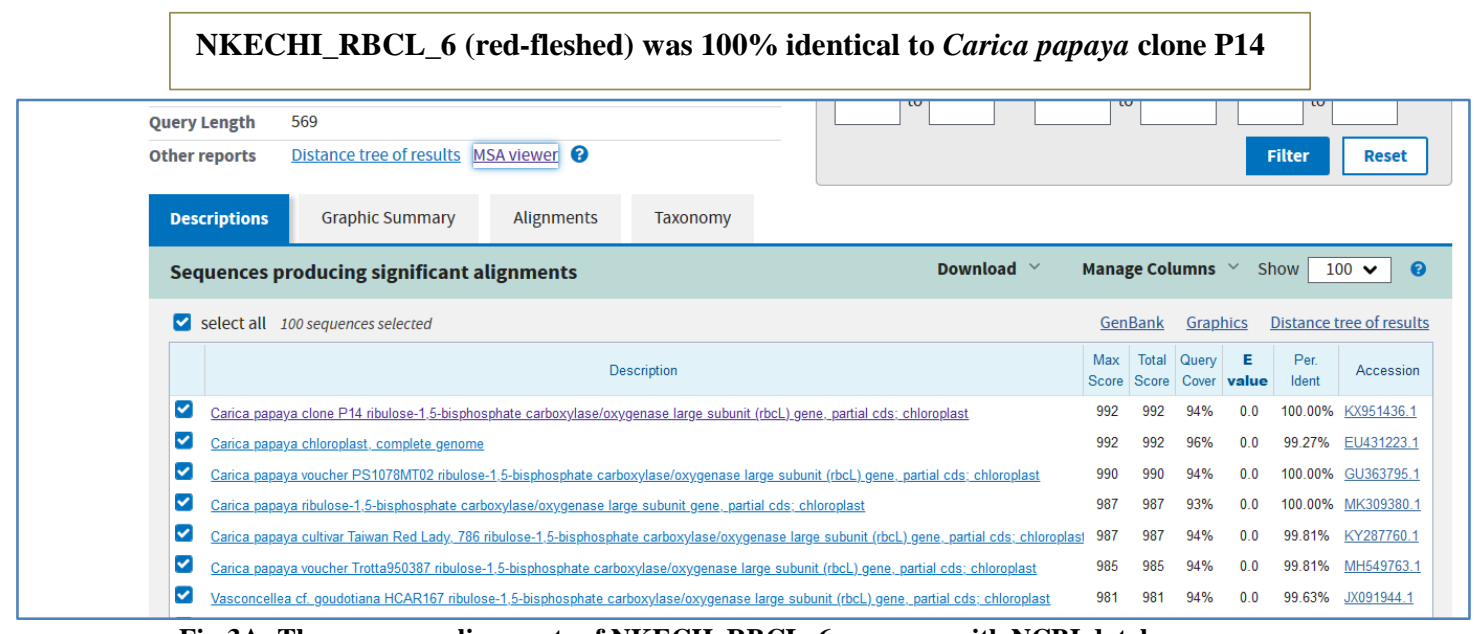

Fig-3A: The sequence alignments of NKECH_RBCL_6 sequence with NCBI database sequence

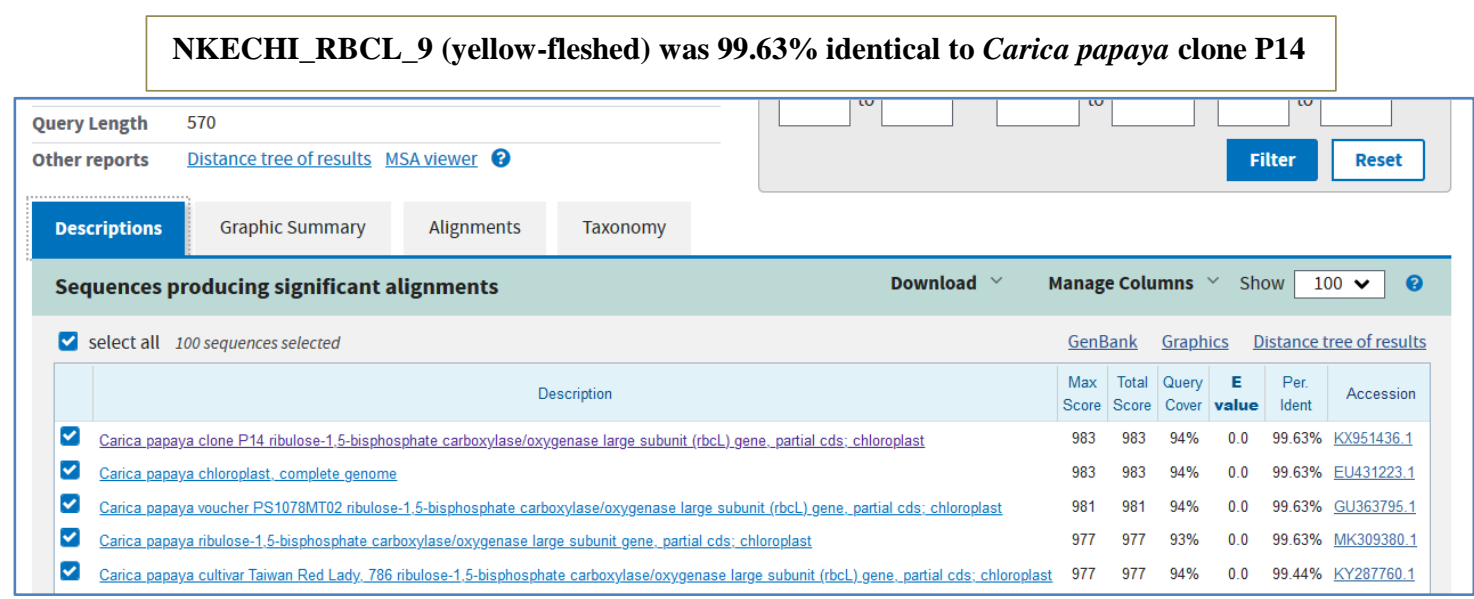

Fig-3B: The sequence alignments of NKECH_RBCL_9 sequence with NCBI database sequence

The result of the pairwise with dots for identities using the alignment view is presented in Figures 4 and 5. In Fig.4 A and B, it was observed that all nucleotides of NKECHI_RBCL_6 sequence aligned perfectly with the sequence Carica papaya clone 14 while all nucleotides accept the nucleotides on position 8 and 9 of Carica papaya clone 14 which is [TT] (red colour) was replaced with [AA] in NKECHI_RBCL_9 sequence. This finding indicates that Carica papaya clone 14 was probably a yellow-fleshed papaya variety.
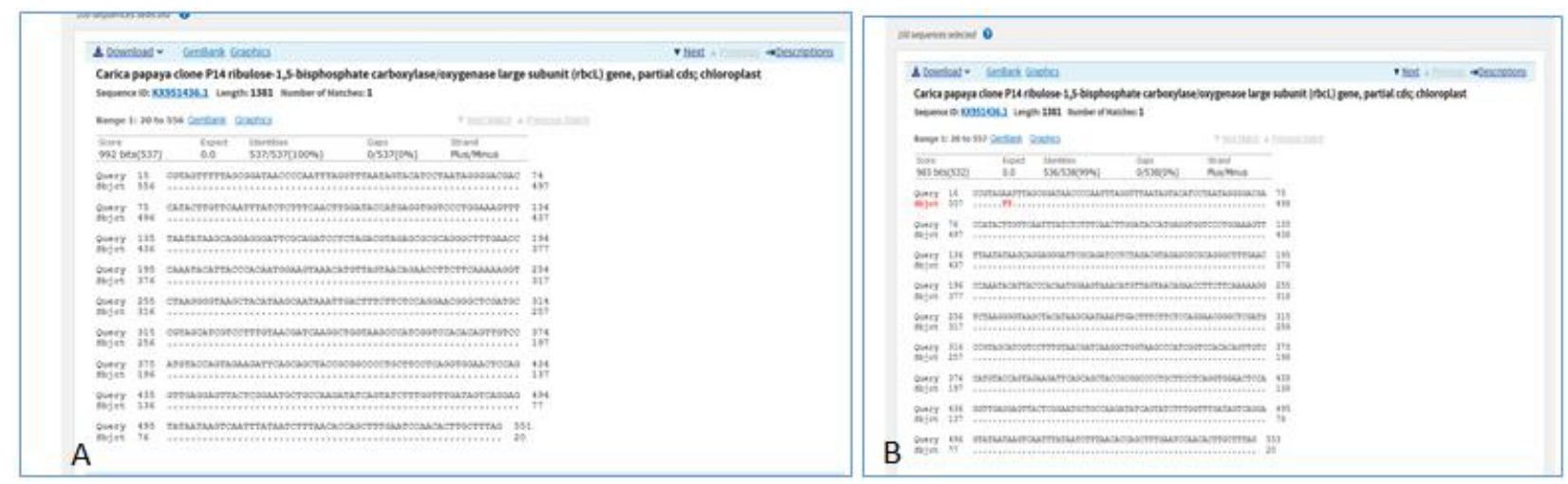

Fig-4: The alignment view of the pairwise with dots for identities of Carica papaya clone 14 sequence to the sequences of A. NKECHI_RBCL_6, and B. NKECHI_RBCL_9. 
Wahua C et al., Sch Acad J Biosci, Feb, 2021; 9(2): 29-35

\section{DISCUSSION}

Genetic diversity within crop species is essential to understand their origin, domestication and evolutionary relationships, and to efficiently develop strategies for the conservation of their genetic resources, and effective crop improvement [9]. The use of molecular markers in characterization of organisms allows the comparison of DNA sequence information between known and unknown species is very much reliable than traditional methods of identification in diversity studies. According to Kumar et al., [11] assessing the diversity of plants at their molecular level will provide information for the molecular database that will be useful for conservation, and crop improvement programs.

The main objective of this study was to genetically delineate the yellow and red-fleshed papaya varieties to establish their phylogenetic relationship and varietal differences using molecular markers. From this study, the taxonomy report confirmed the evolutionary relationship of the yellow- and red-fleshed papaya as belonging to the Caricaeae family and the order Brassicales. Traditionally, the position of Caricaceae within the dicotyledons has been in the order of Violales [12]. Recently however, the use of molecular techniques [13] suggest Caricaceae should be placed within the order Brassicales (Scheldeman [14]. This is confirmed in this study. Also, the use of molecular markers has been useful in determining the variability amongpapaya varieties and the degree of relatedness of some of these cultivars [15]. To authenticate this, the taxonomy report generated from the sequence alignment of the two yellow and red-fleshed papaya varieties, matched Carica papaya and Vasconcella genus. According to Scheldeman [14], Vasconcella species also known as highland papayas, are evergreen pachycaul shrubs or small trees growing 5metres tall, native to South America and have edible fruit similar to papaya. Most species of this genus were treated as Carica $s p$.

From the result of the alignment view, it was observed that all nucleotides of NKECHI_RBCL_6 sequence aligned perfectly $(100 \%)$ with the sequence Carica papaya clone 14 while all nucleotides accept the nucleotides on position 8 and 9 of Carica papaya clone 14 which is [TT] was replaced with [AA] in NKECHI_RBCL_9 sequence. This finding indicates that Carica papaya clone 14 was probably a yellow-fleshed papaya variety. Also observed there was difference in the percentage of identity between the two papaya varieties of $0.47 \%$. The most common explanations for this percentage difference maybe as a result of mutation in the structural gene sequences. According to a study reported by $\mathrm{Lu}$ et al. [16], it was observed that carotenogenic gene mutation occurred in six tomatoes varieties, watermelon, and loquat resulting in segregation of flesh colour.
However in this study, it was interesting that the Ribulose-1, 5-biphosphate carboxylase $(\mathrm{RBCl})$ molecular marker was able to detect this difference between the yellow and red-fleshed papaya varieties.

\section{CONCLUSION}

Papaya (Carica papaya Linn.) is an important crop with high pro-vitamin A carotenoids content. In Nigeria, the major papaya fruit flesh colours observed is the yellow and red-fleshed varieties. Ribulose-1, 5-biphosphate carboxylase $(R B C l)$ molecular marker was able to detect this difference between the yellow and red-fleshed papaya varieties. These findings provide information that will contribute to the molecular database of papaya and will be useful for the papaya conservation and crop improvement programs.

\section{REFERENCES}

1. Nyananyo, 2006

2. Purseglove, 1984

3. Chávez-Pesqueira M, Núñez-Farfán J. Domestication and genetics of papaya: a review. Frontiers in Ecology and Evolution. 2017 Dec $1 ; 5: 155$.

4. Nishimwe G, Kosgei JC, Okoth EM, Ochieng'Asudi G, Rimberia FK. Evaluation of the morphological and quality characteristics of new papaya hybrid lines in Kenya. African Journal of Biotechnology. 2019 Jan 9;18(2):58-67.

5. Devitt LC, Fanning K, Dietzgen RG, Holton TA. Isolation and functional characterization of a lycopene $\beta$-cyclase gene that controls fruit colour of papaya (Carica papaya L.). Journal of Experimental Botany. 2010 Jan 1;61(1):33-9.

6. Ferwerda FP, Wit F. Outlines of perennial crop breeding in the tropics. Veenman; 1969.

7. Schweiggert RM, Steingass CB, Esquivel P, Carle R. Chemical and morphological characterization of Costa Rican papaya (Carica papaya L.) hybrids and lines with particular focus on their genuine carotenoid profiles. Journal of agricultural and food chemistry. 2012 Mar 14;60(10):2577-85.

8. Ming R, Hou S, Feng Y, Yu Q, Dionne-Laporte A, Saw JH, Senin P, Wang W, Ly BV, Lewis KL, Salzberg SL. The draft genome of the transgenic tropical fruit tree papaya (Carica papaya Linnaeus). Nature. 2008 Apr;452(7190):991-6.

9. Moore PH. Phenotypic and genetic diversity of papaya. InGenetics and Genomics of Papaya 2014 (pp. 35-45). Springer, New York, NY.

10. Saghai-Maroof MA, Soliman KM, Jorgensen RA, Allard RW. Ribosomal DNA spacer-length polymorphisms in barley: Mendelian inheritance, chromosomal location, and population dynamics. Proceedings of the National Academy of Sciences. 1984 Dec 1;81(24):8014-8

11. Kumar A, Gayakwad A, Panse U, Khasdeo K, Narayanan C, Ansari SA, Lazarus AD. Optimization of DNA Extraction Methods for Some 
Important Forest Tree Species. International Journal of Advanced Biotechnology and Research. 2013;4(3):364-71.

12. Cronquist A, Takhtadzhian AL. An integrated system of classification of flowering plants. Columbia university press; 1981.

13. Chase MW, Christenhusz MJ, Fay MF, Byng JW, Judd WS, Soltis DE, Mabberley DJ, Sennikov AN, Soltis PS, Stevens PF. An update of the Angiosperm Phylogeny Group classification for the orders and families of flowering plants: APG IV. Botanical Journal of the Linnean Society. 2016 May $1 ; 181(1): 1-20$.
14. Scheldeman X. Distribution and potential of cherimoya (Annona cherimola Mill.) and highland papayas (Vasconcellea spp.) in Ecuador. $\mathrm{PhD}$ Thesis, University of Ghent Belgium. 2002;1-190.

15. OECD. "Section 10 -Papaya (Carica papaya)", in Safety Assessment of Transgenic Organisms, Volume 1: OECD Consensus Documents, OECD Publishing, Paris; 2006.

16. Lu PJ, Wang CY, Yin TT, Zhong SL, Grierson D, Chen KS, Xu CJ. Cytological and molecular characterization of carotenoid accumulation in normal and high-lycopene mutant oranges. Scientific reports. 2017 Apr 10;7(1):1-5. 